\title{
Eat, Fast, and Live Longer!
}

\author{
Françoise Wilhelmi de Toledo
}

Klinik Buchinger Wilhelmi, Überlingen, Germany

The 15th medical congress of the Medical Association for Fasting and Nutrition (German: Ärztegesellschaft Heilfasten und Ernährung, ÄGHE) took place on June 29-30, 2013 in Überlingen, Germany.

This congress was organized in association with the Maria Buchinger Foundation and the Buchinger Wilhelmi Clinics in the course of their anniversary years; 60 years in Überlingen, Germany, and 40 years in Marbella, Spain. Andreas Michalsen, Ph.D., and Françoise Wilhelmi de Toledo, M.D., were the scientific chairpersons.

The congress aimed at giving an overview about fasting as a global contemporary health-enhancing and therapeutic strategy based on science and tradition.

On that occasion the Maria Buchinger Foundation prize was awarded to Valter Longo, Ph.D., professor and director of the USC Davis School of Gerontology at the University of Southern California, Los Angeles, CA, USA, for his work on fasting and longevity as well as fasting against cancer.

The congress was opened by the president of the ÄGHE, Eva Lischka, M.D., who welcomed 400 international guests. A translation of the lectures into English, French, and German was provided, and the presentations are available online at www.fasten.tv.

The first lecture by Françoise Wilhelmi de Toledo gave an overview of the Buchinger fasting, the most used fasting methods [1] nowadays. These fasting methods [2] emerged out of a personal self-healing experience at the turn of the 21 st century in Germany. Otto Buchinger, a navy medical officer, suffered from disabling rheumatic fever. His generalized joint inflammation was cured in the course of a 19-day fasting cure in 1919 without relapse. This happened in the context of the lifestyle reform movement (Lebensreformbewegung), a popular German movement in the beginning of the 20th century reflecting the increasing awareness towards environmental pollution of industrialized cities and the search for nature, healthy lifestyle, and natural healing methods. Buchinger built his own first fasting sanatorium in Northern Germany in Bad Pyrmont, after- wards in Überlingen in 1953, and finally also in Marbella in 1973. This multidisciplinary institution was developed by 3 family generations in collaboration with medical experts. Especially Heinz Fahrner, M.D., and the following generations were keen to merge their huge clinical experience with science. Today, there are more than 4,000 patients per year experiencing prolonged fasting in both institutions. Numerous publications and books were published since 1935. The ÄGHE, which consists of 150 members, was founded in 1986. The first guidelines for fasting therapy were developed in consensus by 20 experts and published in 2002 [3]. Partnerships between universities and their departments for integrative medicine and naturopathy (e.g. Berlin, Essen, Zürich, Jena, Freiburg i. Br., Strasburg, and Granada) and the Buchinger clinics developed.

In the 1980s, a movement of non-medical fasting emerged, triggered by Hellmut Lützner, M.D. These licensed fasting guides, who follow a defined educational training, offer a 1-week fast for healthy people, conducted in small hotels or convents, sometimes in combination with hiking. The Buchinger Clinics, a few other fasting clinics, and the guides have built up what could be called the fasting ecosystem. Nowadays, fasting-mimicking and enhancing diets (FMED) are being developed in order to motivate people to fast without having to completely renounce food. Although this may seem contradicting, these low-calorie diets with a special composition have some of the metabolic and neurohormonal effects of fasting, like diminishing fat mass, enhancing insulin sensitivity, boosting stem cells, and reducing activity of some aging pathways. They can of course not replace the holistic effects of a whole fasting process, but could help people maintaining the good results on the long run.

The next lecture was given by the Maria Buchinger Foundation 2013 Award winner Valter Longo. He started his career by studying calorie restriction and longevity at Roy Walford's laboratory. He found that living with $30 \%$ less calories was reducing high blood pressure, diabetes, cardiovascular diseases,

\section{KARGER \\ Fax +497614520714 \\ Information@Karger.com}

www.karger.com (c) 2013 S. Karger GmbH, Freiburg

$1661-4119 / 13 / 0206-0462 \$ 38.00 / 0$

Accessible online at:

www.karger.com/fok
Françoise Wilhelmi de Toledo, M.D.

Klinik Buchinger Wilhelmi

Wilhelm-Beck-Straße 2

788662 Überlingen, Germany

francoise.wilhelmi@buchinger.com 
and obesity, all in one. Instead of 10 different drugs, only 1 health-enhancing procedure would be required. Because lifelong renouncement to full satiety is not easy to achieve, intermittent fasting was considered as an alternative. Initially, Longo studied yeasts and screened their 6,000 genes in search of aging pathways [4]. He worked on the RAS 1.2-PKA pathways showing that they suppress protective and repair genes in presence of glucose, proteins, and growth factors like IGF1. After replacing glucose with water, yeasts lived twice as long, and their repair functions were activated. Similar results were discovered by deactivating the RAS pathways by means of mutations. Longo and coworkers discovered the gene $\mathrm{SCH} 9$ as part of the TOR/SK6 pro-aging pathway: when deactivated, the yeast mutants lived 3 times longer, were multistress resistant against all types of oxidative, physical (like heat shocks), and toxic stresses, and remained small in size. If deactivation of the aging pathways and fasting are combined, yeasts mutants can live up to 10 times longer. Later on, Longo studied a population of Ecuadorians suffering from Laron syndrome, a congenital condition where receptors of growth hormone production are impaired. The people affected are very low in size but have no age-related diseases like diabetes, cardiovascular disease, or cancer.

The multiple stress resistance of yeasts and mice was also proved by injecting chemotherapy drugs like doxorubicine and cisplatin [5]. This made Longo and his coworkers study the effect of fasting on cancer cells. The results showed that cancer cells are more vulnerable to chemotherapy during the fasting period [6]. The fasting-induced acute weight loss could be compensated soon, whereas the control group who received chemotherapy lost weight continuously, without regaining it. Finally, Longo could demonstrate that fasting protects against chemotherapy-induced side effects $[7,8]$ and neuronal damages like behavioral deficiencies and deficits in motor coordination, learning, and memory. Stem cells regeneration had been demonstrated, and enhanced synapse plasticity was suggested. Currently, several clinical trials are being conducted with fasting periods as well as with periods of FMED.

After the award ceremony the scientific program was further managed by Rainer Stange, M.D., vice president of the ÄGHE.

Andreas Michalsen gave an overview about the current state of clinical evidence of fasting therapy [9]. Whereas for some indications like rheumatoid arthritis [10] or hypertension evidence is increasing, in other areas clinical research and evidence provided by controlled trials is needed.

Michael Boschmann, M.D., stressed the fact that not only nutritional factors and fasting play a role in anti-aging and protection against disease but also circadian rhythms and biorhythms as well as exercise [11]. The same food taken at different times may have different effects; and for the efficiency of fasting in order to achieve weight loss, preserving fat-free mass and enhancing insulin sensitivity exercise play an essential role.

Eat, Fast, and Live Longer!
Gustav Dobos, Ph.D., stressed the effectiveness of fasting in enhancing the 'perceived self-efficacy' and thus the faith in one's own self-healing power. Mind/body medicine may further enhance the effects of fasting especially in a setting with professional guidance.

Yvon Le Maho, Ph.D., described a great diversity in fasting strategies of wildlife, especially among the king and emperor penguins. He came to the conclusion that fasting is a survival strategy that is present in any living being [12]. He observed 3 phases in animal fasting: the glycogen short first phase; the fat/ protein second phase, dominated by the switch to ketone bodies as fuel and the protein sparing mechanisms; and finally, after several weeks of fasting in case of humans, phase 3, characterized by rapid protein catabolism, which requires soon refeeding.

Markus Bock, M.D., presented the ketogenic diet, a highfat, low-glucose diet with variable amounts of proteins. It has proved its efficacy in treating epileptic seizures and is used in combination with short-term fasting periods in children with drug incompatibility. A ketogenic diet seems to be promising in the course of treating diseases like multiple sclerosis. Bock underlined the importance of absorbing natural fats of high quality which are rich in especially omega 3 and 6 in the right proportion.

Finally, nutrition was also addressed as a corollary of fasting. Claus Leitzmann, Ph.D., made a clear synthesis of what a good nutrition means today [13], stressing the importance of considering other dimensions than the mere improvement of human health. From the ecological point of view, food production has to be sustainable and should not waste resources like water, energy or produce environmental pollution. Furthermore, food production should take into account ethical values like the fair distribution of earth resources and the interdiction of animal abuse.

Michaela Döll, Ph.D., introduced a way of food selection in order to diminish inflammatory processes [14], either by eating selected nutrients like berries (e.g., acai and goji beeries), pomegranate, and vegetables like broccoli or ginger and nuts. Furthermore, sweets, cakes or processed foods made with saturated fats should be avoided. She described fasting as a potent anti-inflammatory procedure.

Further speakers of the congress were José Manuel García Verdugo, M.D., who presented his experience and the history of fasting within the perspective of the Buchinger Wilhelmi Clinics in Marbella, and Eva Lischka, who presented selected clinical cases. Gudrun Mussehl gave insights into the current practice and training of fasting guides. Sylvie Gilman presented her film, made for the TV chain Arte [15]. Finally, Stanislav Muraviev, M.D., presented the Russian experience in fasting therapy against hypertension in obese patients.

Niklaus Brantschen S.J. recalled the multiple dimensions of fasting, i.e. medical, communitarian, and spiritual [16]. Brantschen outlined that fasting and religion have the same origins. Fasting directs our thoughts inwards, leading to silence 
and to the divine within us. Religious rituals, prayers, and group dynamics can steer fasting in the right direction. Brantschen stated that a prayer rises within us, and that our heart soars when we find a way to silence through fasting. As a fasting guide, he offers fasting courses including meditation and silence, and he organizes regular workshops for fasting guides in church.

Françoise Wilhelmi de Toledo

\section{Program Overview}

All lectures can be viewed at www.fasten.tv:

- Françoise Wilhelmi de Toledo, Überlingen: The ecosystem fasting and the flagships Buchinger 60/40 years

- José Manuel García Verdugo, Marbella:The ecosystem fasting and the flagships Buchinger 60/40 years

- Andreas Michalsen, Berlin: Clinical research on fasting and scientific evidence

- Gustav Dobos, Essen: Fasting as part of mind/body medicine

- Valter Longo, Los Angeles, CA: Award speech: fasting, longevity, and cancer
- Michael Boschmann, Berlin: Impact of feeding regimens and circadian rhythms on aging and longevity

- Gudrun Mussehl, Illmensee: Fasting in a group, health education, training for fasting guides

- Yvon Le Maho, Strasbourg: Different forms of caloric restriction and seasonal fasting in the animal world

- Stanislav Muraviev, Tyumen: Fasting therapy effectiveness against hypertension in obese patients

- Niklaus Brantschen J.S., Bad Schönbrunn: Fasting, a treasure buried in the garden of the church. The spiritual dimension of fasting

- Sylvie Gilman, Paris: About the ARTE film: 'Science of Fasting' - traditional clinical experience and latest scientific evidence

- Claus Leitzmann, Giessen: Wholefood nutrition - a contemporary and sustainable way of understanding human nutrition

- Michaela Döll, Wachenheim: Inflammation - fasting and effective anti-inflammatory food components

- Markus Bock, Berlin: Sugar fasting - ketogenic diet as a strategy for the therapy of neurologic diseases

- Eva Lischka, Überlingen: Case reports of fasting therapy

- Award ceremony: Valter Longo receives the Maria Buchinger Foundation Award 2013; laudation by Yvon Le Maho

\section{References}

1 Wilhelmi de Toledo F: Therapeutic Fasting: The Buchinger Amplius Method. Stuttgart, Thieme, 2012.

2 Wilhelmi de Toledo F, Friebe R, Hebisch D, Kuhn C, Platzer G, Scharg S: The Klinik Buchinger programme for the treatment of obesity; in Ditschuneit H, Gries FA, Haunter H, Schusziarra V, Wechsler JG, (eds): Obesity in Europe 1993. London, Libbey, 1994, pp 289-293.

3 Wilhelmi de Toledo F, Buchinger A, Burggrabe H, et al.: Leitlinien zur Fastentherapie. Forsch Komplementärmed Klass Naturheilkd 2002;9:189-198.

4 Fontana L, Patridge L, Longo V, et al.: Extending healthy life span - from yeast to humans. Science 2010;328:321-326.

5 Raffaghello L, Safdie F, Longo V, et al.: Fasting and differential chemotherapy protection in patients. Cell Cycle 2010;9:4474-4476.
6 Lee C, Raffaghello L, Longo V, et al.: Fasting cycles retard growth of tumors and sensitize a range of cancer cell types to chemotherapy. Sci Transl Med 2012;4:124ra127.

7 Safdie F, Dorff T, Longo V, et al.: Fasting and cancer treatment in humans: a case series report. Aging (Albany NY) 2009;1:988-1007.

8 Raffaghello L, Lee C, Longo V, et al.: Starvation-dependent differential stress resistance protects normal but not cancer against high-dose chemotherapy. Proc Natl Acad Sci USA 2008;105: 8215-8220.

9 Michalsen A, Chenying L: Fasting therapy for trating and preventing disease - current state of evidence. Forsch Komplementmed 2013;20:444-453.

10 Müller HF, Wilhelmi de Toledo F, Resch KL: Fasting followed by vegetarian diet in patients with rheumatoid arthritis a systematic review. Scand J Rheumatol 2001;30:1-10.
1 Steiniger J, Schneider A, Bergmann S, Boschmann M, Janietz K: Einfluss von therapeutischem Fasten und Ausdauertraining auf den Energiestoffwechsel und die körperliche Leistungsfähigkeit Adipöser. Forsch Komplementmed 2009;16:383-390.

12 Le Maho Y: Le manchot empereur: un exemple d'adaptation au jeûne de longue durée. Cah Nutr Diet 1998:33:225-226.

13 von Koerber K, Männle T, Leitzmann C: VollwertErnährung. Konzeption einer zeitgemäßen Ernährungsweise, ed 9. Heidelberg, Haug, 1994.

14 Doell M: Warum Papaya kühlt und Zucker heiß macht. München, Herbig, 2013

15 Gilman S, de Lestrade T: Science of Fasting (Film). Arte, 2012.

16 Brantschen N: Fasting: What, Why, How. New York, Crossroad Publishing Company, 2010. 